\title{
Model Pengelolaan Eucalyptus pellita pada Hutan Industri Berkelanjutan
}

\author{
Prisma Yudistira*, Mahawan Karuniasa, Yuki Mahardhito Adhitya Wardhana \\ Sekolah Ilmu Lingkungan Universitas Indonesia \\ Jl. Salemba Raya No. 4, Kampus UI Salemba, Jakarta Pusat
}

Diterima : 31 April 2019, Revisi akhir : 05 Juni 2019, Disetujui terbit : 28 Juni 2019

Management Model of Eucalyptus pellita in Sustainable Industrial Forest

\begin{abstract}
PT. X is one of the Industrial Plantation Forest companies that obtained a permit covering 296,262 ha. The objective of this study is to develop a model for sustainable industrial plantation management focused on Eucalyptus pellita plantation in Rasau Kuning district, Riau Province.The method used is the Analytical Hierarchy Process (AHP) as a method in the industrial plantation management model. The results showed AHP analysis of the role of silviculture, income of precarious workers, education and training on the potential of stands was silviculur with a value (0.523). AHP analysis on sustainable industrial plantation management with priority alternative results is production facilities and infrastructure (0.408) in industrial plantation management. This research proves that silvicultural criteria and alternative production facilities and infrastructure have a major role in the sustainable industrial plantation management model.
\end{abstract}

Keywords : industrial plantation forests, potential of stands, sustainability

\begin{abstract}
Abstrak
PT. X adalah salah satu perusahaan pengelola Hutan Tanaman Industri (HTI) yang mendapatkan ijin seluas 296.262 ha. Penelitian ini bertujuan untuk menyusun model pengelolaan hutan tanaman industri yang berkelanjutan berfokus pada Eucalyptus pellita pada distrik Rasau Kuning, Provinsi Riau. Penelitian ini berfokus pada Eucalyptus pellita pada distrik Rasau Kuning, Provinsi Riau. Metode yang digunakan adalah Analytical Hierarchy Process (AHP) sebagai metode dalam model pengelolaan hutan tanaman industri. Aspek yang menjadi pembahasan dalam penelitian ini adalah peran silvikultur, pendapatan pekerja tidak tetap, pendidikan dan pelatihan, sarana dan prasarana produksi. Hasil penelitian menunjukkan bahwa analisis AHP terhadap peran silvikultur, pendapatan pekerja tidak tetap, pendidikan dan pelatihan terhadap potensi tegakan adalah silvikulur dengan nilai $(0,523)$. Analisis AHP pada pengelolaan hutan tanaman industri yang berkelanjutan dengan hasil alternatif prioritas adalah sarana dan prasarana produksi $(0,408)$ pada pengelolaan hutan tanaman industri. Penelitian ini membuktikan kriteria silvikultur dan alternatif sarana dan prasarana produksi mempunyai peran utama dalam model pengelolaan hutan tanaman industri yang berkelanjutan.
\end{abstract}

Kata kunci: hutan tanaman industri, potensi tegakan, keberlanjutan 


\section{Pendahuluan}

Hutan sebagai sumber daya alam mempunyai manfaat yang penting bagi kehidupan manusia baik secara ekonomi, ekologi, dan sosial. Undang-Undang Nomor 41 Tahun 1999 Pasal 6 menyebutkan bahwa hutan mempunyai tiga fungsi yaitu fungsi produksi, fungsi lindung, dan fungsi konservasi. Kelimpahan bahan baku dan kebijakan pemerintah yang berorientasi untuk meningkatkan nilai produk olahan hasil hutan sehingga mengakibatkan kegiatan produksi meningkat. Eksplorasi berlebihan dapat menyebabkan kerusakan hutan yang dapat menyebabkan penurunan produksi kayu, rusaknya spesies biologis dan kebakaran hutan (Putra, Purnomo and Widiyatno, 2014). Menurut The International Bank for Reconstruction and Development (2006), pada tahun 1980 sampai 1997 di dalam beberapa penelitian kerusakan hutan mencapai 500.000 sampai dengan 3.000.000 hektar setiap tahun dan pada tahun 2000 hutan Indonesia tersisa 120 juta hektar.

Berdasarkan kondisi hutan yang rusak tersebut maka diperlukan sebuah kebijakan yang diharapkan dapat mengembalikan kualitas sekaligus meningkatkan produktivitas sumber daya hutan dengan diterbitkannya Peraturan Pemerintah Nomor 7 tahun 1990 tentang Pengusahaan Hutan Tanaman Industri (HTI). HTI diartikan sebagai hutan tanaman yang dibangun dengan menggunakan tanaman jenis fast growing spesies dalam rangka meningkatkan potensi dan kualitas hutan produksi dengan menerapkan silvikultur intensif untuk memenuhi kebutuhan bahan baku hasil hutan. Menurut Indartik, Parlinah dan Lugina (2011), kebijakan pembangunan HTI bertujuan untuk meningkatkan produktivitas hutan produksi dalam rangka pemenuhan bahan baku industri perkayuan, industri pulp dan kertas, dan penyediaan lapangan usaha dan lapangan kerja. HTI berperan dalam pelestarian hutan yang non aktif kemudian melakukan penanaman dengan tanaman jenis-jenis cepat tumbuh dengan tujuan untuk mempercepat produktivitas hutan dan mencukupi penyediaan kebutuhan kayu bagi industri (Suhartati et al., 2013).

Salah satu perusahaan yang mengelola hutan tanaman industri terluas di provinsi Riau yaitu PT. X dengan luas 296,262 hektar. Pengusahaan HTI PT. X tumbuh dan mampu menjadi perusahaan yang terintegrasi dengan salah satu industri pulp. Jenis spesies yang digunakan oleh PT. X adalah jenis-jenis tanaman pioneer yang mampu berkembang dan mampu membantu dalam upaya perbaikan lingkungan. Salah satu jenis tanaman unggul di PT. X adalah Eucalyptus sp. yang dikembangkan untuk industri pulp dan kertas. Kriteria jenis hutan tanaman untuk pulp dan kertas, yaitu jenis cepat tumbuh, produktivitas tinggi, daur pendek dan memiliki sifat (kimia dan fisika) kayu sesuai dengan persyaratan bahan baku industri pulp dan kertas (Mindawati, 2011). Kayu untuk pulp dan kertas harus memiliki serat yang panjang, kandungan lignin yang relatif rendah, rendemen yang tinggi serta kekuatan yang dihasilkan tinggi (Pasaribu and Tampubolon, 2007). Eucalyptus sp. cocok dikembangkan di daerah tropis (Leksono, 2010), dipanen pada umur 6-7 tahun (Suprapti, Djarwanto and Pasaribu, 2008), dan layak untuk bahan baku pulp pada umur 4-5 tahun (Leksono, 2010). Pada jenis Eucalyptus pellita ditarget pada tahun 2014 mencapai volume sebesar $145 \mathrm{~m}^{3}$ per hektar dengan nilai MAI di atas $35 \mathrm{~m}^{3}$ per hektar.

Pembangunan HTI membutuhkan dukungan dari kegiatan silvikultur, para pekerja dan pengelolaan kondisi tempat tumbuh karena akan mempengaruhi dalam upaya mengoptimalkan potensi hutan (Wahyuni and Indriyanti, 2015). Keberhasilan dalam pengelolaan hutan tanaman industri didukung dengan sarana dan prasarana produksi, jarak tanam yang optimal, dan kualitas dari pekerja teknis dilapangan, maka dalam upaya untuk mendorong peningkatan potensi hutan tanaman industri perlu penelitian mengenai model pengelolaan hutan tanaman industri berkelanjutan (Suhartati et al., 2013). Penelitian ini bertujuan untuk meyusun model pengelolaan hutan tanaman industry untuk produksi pulp yaitu Eucalyptus pellita.

\section{Bahan dan Metode}

Data penelitian adalah data primer dan data sekunder. Data primer terdiri atas data pengelolaan tegakan hutan tanaman industri yang meliputi aspek silvikultur, jarak tanam, pendidikan dan pelatihan, pendapatan pekerja tidak tetap, sarana dan prasarana produksi, dan tempat tumbuh di lokasi PT. X. Data sekunder berupa berbagai studi literatur terkait dengan potensi tegakan Eucalyptus pellita.

\section{Metode Analytical Hierarchy Process (AHP)}

Metode AHP digunakan untuk menganalisis peran silvikultur, pendapatan pekerja tidak tetap, 
pengelolaan tempat tumbuh dan peran model tanaman industri yang berkelanjutan. Metode ini digunakan karena AHP dapat mengkuantifikasi data kualitatif yang diperoleh responden, dan struktur hierarki dapat dengan mudah dipahami oleh responden ahli dalam melakukan perbandingan berpasangan. Perbandingan AHP dilakukan dengan cara membandingkan antara elemen yang satu dengan lain pada setiap tingkatan (Djunaidi, Sholeh and Mufiid, 2018). Pada penelitian ini, kriteria yang akan dibandingkan adalah silvikultur, pendapatan pekerja tidak tetap, tempat tumbuh. Selanjutnya alternatif yang dibandingkan adalah sarana dan prasarana produksi, jarak tanam, pendidikan dan pelatihan. Nilai setiap perbandingan ditentukan berdasarkan persepsi sampel penelitian. Setiap bobot yang diberikan oleh sampel penelitian telah diatur oleh Thomas L. Saaty sebagaimana dapat dilihat pada Tabel 1.

Berdasarkan Tabel 1 dapat dijelaskan bahwa nilai perbandingan pada metodologi AHP adalah 1 sampai 9. Nilai 1 artinya sesuatu yang dibandingkan tingkat kepentingannya sama. Nilai 3 artinya salah satu pilihan sedikit lebih penting dibanding pilihan lainnya. Angka 5, 7, dan 9 nilai kepentingannya adalah masingmasing lebih penting, sangat penting, mutlak penting. Nilai 2, 4, 6, 8 adalah nilai kompromi jika kepentingannya terletak antara nilai $1,3,5$, 7, dan 9.

Setiap hasil kuisioner akan dilakukan uji konsistensi. Uji konsistensi bertujuan untuk melihat korelasi antara setiap perbandingan

Tabel 1. Intensitas Tingkat Kepentingan Metode AHP

\begin{tabular}{lc}
\hline $\begin{array}{l}\text { Intensitas } \\
\text { Tingkat } \\
\text { Kepentingan }\end{array}$ & Definisi \\
\hline 1 & Sama penting \\
3 & Sedikit lebih penting \\
5 & Lebih penting \\
7 & Sangat lebih penting \\
9 & Mutlak lebih penting \\
$2,4,6,8$ & Nilai kepentingan yang \\
Nilai Kebalikan & mencerminkan nilai kompromi \\
& Nilai tingkat kepentingan jika \\
& dilihat dari arah berlawanan. A \\
& lebih penting dari B (intensitas \\
& 5), maka B kurang penting \\
& dibanding A (intensitas 1/5) \\
\hline
\end{tabular}

yang dilakukan. Nilai konsistensi diperlukan untuk memastikan jawaban setiap pertanyaan dilakukan secara benar. Setiap kuesioner dapat dikategorikan konsisten jika nilai rasio konsistensi (CR) lebih kecil daripada atau sama dengan $10 \%(\leq 10 \%)$.

\section{Hasil dan Pembahasan}

Hasil penilaian AHP bersama dengan wawancara mendalam dari pakar digunakan sebagai dasar dalam perumusan kebijakan model pengelolaan hutan tanaman industri yang berkelanjutan, dapat dilihat pada Gambar 1.

Nilai RI berdasarkan tabel yang dikembangkan oleh Thomas L. Saaty sebagaimana dapat dilihat pada Tabel 2.

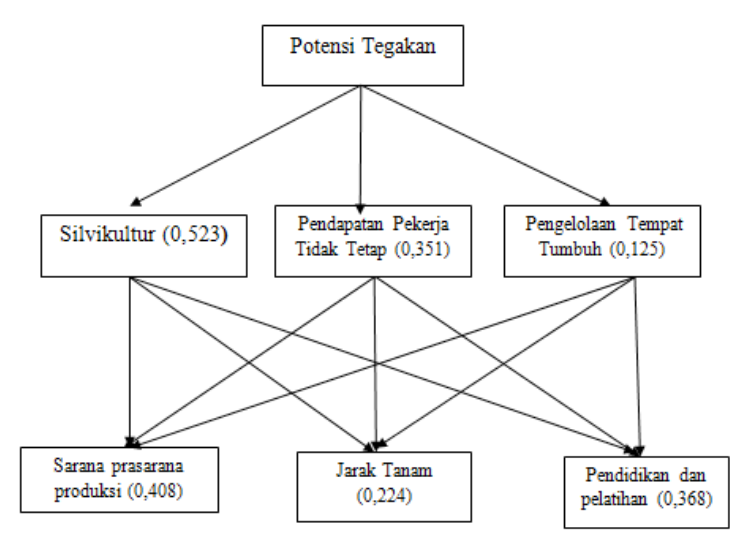

Gambar 1. Model AHP Penelitian

Tabel 2. Nilai Rasio Konsistensi (RI)

\begin{tabular}{lc}
\hline $\mathrm{N}$ & Nilai Rasio Konsistensi (R1) \\
\hline 1 & 0,00 \\
2 & 0,00 \\
3 & 0,58 \\
4 & 0,90 \\
5 & 1,12 \\
6 & 1,24 \\
7 & 1,32 \\
8 & 1,41 \\
9 & 1,45 \\
10 & 1,49 \\
11 & 1,51 \\
12 & 1,48 \\
13 & 1,56 \\
14 & 1,56 \\
15 & 1,59 \\
\hline
\end{tabular}


Kebijakan pengelolaan hutan tanaman industri yang berkelanjutan menggunakan indikator potensi tegakan sebagai ukuran keberlanjutan. Pembangunan hierarki menggunakan kriteria ekonomi, sosial dan lingkungan yang berpengaruh pada tujuan potensi tegakan. Penilaian alternatif prioritas pada kebijakan model pengelolaan hutan tanaman industri yang berkelanjutan menggunakan metode AHP. Hasil penilaian AHP bersama dengan wawancara mendalam dari pakar digunakan sebagai dasar dalam perumusan kebijakan model pengelolaan hutan tanaman industri yang berkelanjutan.

Kebijakan pengelolaan hutan tanaman industri yang berkelanjutan menggunakan indikator potensi tegakan sebagai ukuran keberlanjutan. Pembangunan hierarki menggunakan kriteria ekonomi, sosial dan lingkungan yang berpengaruh pada tujuan potensi tegakan. Kriteria ini meliputi silvikultur, pendapatan pekerja tidak tetap dan tempat tumbuh. Alternatif dipilih beradasarkan aspek sarana dan prasarana produksi, jarak tanam, pendidikan dan pelatihan. Penilaian terhadap perbandingan berpasangan kriteria dan alternatif prioritas dilakaukan oleh responden ahli yang terdiri atas kelompok pekerja tidak tetap, stakeholders ahli dan ahli akademisi yang seluruhnya berjumlah 4 orang. Hasil penilaian yang dilakukan oleh responden ahli menunjukkan bahwa silvikultur adalah kriteria yang paling penting dalam mendukung keberlanjutan pengelolaan hutan tanaman industri dengan nilai 0,523, urutan kedua adalah pendapatan pekerja tidak tetap dengan nilai 0,351 dan yang terkahir tempat tumbuh dengan nilai 0,125 . Pendapatan pekerja tidak tetap dan tempat tumbuh adalah kriteria yang juga penting dalam mendukung keberlanjutan.

Pada penilaian kriteria silvikultur, pendapatan pekerja tidak tetap, pengelolaan tempat tumbuh menunjukkan bahwa silvikultur merupakan kriteria yang paling penting dalam pengelolaan hutan tanaman industri yaitu sebesar 0,523. Pelaksanaan kegiatan operasional silvikultur di distrik Rasau Kuning sangat mempertimbangkan kondisi biofisik dan sosial areal kerja. Sistem yang diterapkan adalah Tebang Habis dengan Permudaan Buatan (THPB). Kegiatan silvikultur pada tahun 2018 membutuhkan tenaga kerja sekitar 1000 orang. Pada tahun 2018 kegiatan pengendali hama dan penyakit menjadi perhatian utama dikarenakan pada tahun 2017 mengalami serangan monyet yaitu monyet ekor panjang
(Macaca fascicularis) sebanyak 50 ekor dengan lokasi berpindah-pindah sekitar distrik Rasau Kuning. Jenis penyakit yang menyerang Eucalyptus pellita distrik Rasau Kuning adalah jamur akar kayu putih. Kegiatan silvikultur sangat mempengaruhi kegiatan produksi hutan tanaman industri. Penelitian ini sejalan dengan penelitian yang dilakukan oleh Leksono (2010), yang menjelaskan bahwa kegiatan produksi sangat dipengaruhi oleh luas target penanaman, bibit, pupuk, herbisida dan tenaga kerja yang optimal. Pada kegiatan silvikultur mempunyai pengukuran kerja yang dituangkan dalam prestasi kerja (Yuniati, 2011). Pengukuran prestasi kerja berdasarkan waktu yang dibutuhkan standar yang dapat membuktikan pekerja yang bersangkutan telah berkinerja pada level yang diinginkan, sedangkan bagi pegawai merupakan garansi bahwa mereka akan diberikan kompensasi yang sesuai dengan kinerja yang telah mereka hasilkan. Prestasi kerja sebagai bahan acuan dalam pengambilan keputusan pihak perencanaan meliputi perencanaan tenaga kerja produksi, perencanaan proses produksi, dan penentuan sistem insentif dalam suatu perusahaan.

Pendapatan pekerja tidak tetap atau kontraktor merupakan unsur penting keberhasilan dari pengelolaan hutantanaman industri. Hutantanaman industri menjadi salah satu andalan pemasukan devisa dalam pengentasan kemiskinan, di sisi lain sistem upah borongan dipilih oleh perusahaan agar dapat mengawasai secara langsung. Sistem upah borongan yang dilakukan oleh pengusaha hutan tanaman industri biasanya akan memberikan dampak terjadi persaingan masing-masing untuk bekerja lebih baik. Segi kontrak pekerjaan, apabila pekerjaan pemborong tidak baik maka pengusaha hutan tanaman industri dapat memberikan sanksi, namun apabila perkerjaan yang dilakukan oleh pemborong baik maka akan diberikan pekerjaan sehingga mempunyai peluang untuk mendapatkan keuntungan.

Aspek jarak tanam sangat berpengaruh terhadap pertumbuhan suatu tegakan semakin lebar jarak tanam maka nilai rataan diameter tegakan akan semakin bertambah besar. PT. $\mathrm{X}$ jarak tanam tegakan adalah $3 \mathrm{~m}$ x 2,5 $\mathrm{m}$ hal tersebut dikarenakan agar jumlah pohon yang dihasilkan lebih banyak persatuan luas. Pada PT. $\mathrm{X}$ pendidikan dan pelatihan perlu diperhatikan untuk pekerja tidak tetap, hal tersebut dikarenakan kemampuan tenaga kerja akan berpengaruh terhadap tanaman yang akan dihasilkan. 
Hasil temuan potensi tegakan menunjukkan volume sebesar $137 \mathrm{~m}^{3}$ per hektar, nilai tersebut masih di bawah dari roadmap KLHK dan penelitian Suhartati et al. (2013) yaitu sebesar $197 \mathrm{~m}^{3}$ per hektar. Rendahnya potensi tegakan disebabkan masih kurangnya upaya dalam peningkatan sarana dan prasarana produksi khususnya dalam memperbaharui alat yang sudah lama. Kegiatan pembangunan dimulai dari tahap perencanaan sampai dengan terbentuknya hutan tanaman industri dalam satu atau dua unit kegiatan kelestarian produksi (Damayatanti, 2011). Pada sasaran dari sarana dan prasarana kegiatan pembangunan adalah mendukung agar terciptanya tegakan hutan tanaman industri dengan kondisi yang mendekati tegakan normal. Kegiatan pengelolaan terdiri atas kegiatan permudaan, pemeliharaan, dan penebangan. Pada sasaran dari sarana dan prasarana produksi adalah mendukung agar tegakan yang akan dihasilkan berkualitas tinggi.

\section{Kesimpulan}

Hasil penelitian ini menunjukkan bahwa potensi tegakan Eucalyptus pellita di distrik Rasau Kuning mempunyai potensi volume sebesar $137 \mathrm{~m}^{3}$ per hektar, nilai tersebut lebih kecil dibandingkan dengan roadmap Kementerian Lingkungan Hidup dan Kehutanan yaitu sebesar $145 \mathrm{~m}^{3}$ per hektar. Hasil analisis AHP pada pengelolaan hutan tanaman industri yang berkelanjutan dengan hasil alternatif prioritas adalah sarana dan prasarana produksi $(0,408)$ pada pengelolaan hutan tanaman industri. Alternatif kedua pendapatan pekerja tidak tetap $(0,351)$, dan ketiga pengelolaan tempat tumbuh $(0,125)$ dan alternatif ketiga jarak tanam $(0,224)$.

\section{Daftar Pustaka}

Damayatanti, P. T. (2011) 'Upaya Pelestarian Hutan Melalui Pengelolaan Sumber daya Hutan Bersama Masyarakat', International Journal of Indonesian Society and Culture, 3(1), pp. 70-82. doi: 10.15294/komunitas. v3i1.2296.

Djunaidi, M., Sholeh, M. A. A. and Mufiid, N. M. (2018) 'Analysis of green supply chain management application in Indonesian wood furniture industry', in AIP Conference Proceedings. AIP Publishing LLC, p. 020050: 1-7. doi: 10.1063/1.5042906.
Endom, W. and Nitibaskara, T. U. (2014) 'Pemanenan Kayu Eko-Efisien di Hutan Alam Mendukung Ketahanan Pembangunan Nasional Berkelanjutan', Jurnal Nusa Sylva, 14(2), pp. 8-16.

Hidayat, H. (2008) Politik Lingkungan: Pengelolaan Hutan Masa Orde Baru dan Reformasi. Yayasan Pustaka Obor Indonesia.

Indartik, I., Parlinah, N. and Lugina, M. (2011) 'Upaya Pembangunan Hutan Tanmaan Industri Untuk Penurunan Emisi Karbon', Jurnal Penelitian Sosial dan Ekonomi Kehutanan, 8(2), pp. 139-147.

Iskandar, U., Ngadiono, N. and Nugraha, A. (2003) Hutan tanaman industri : di persimpangan jalan. Cet. 1. Jakarta: Arivco Press.

Leksono, B. (2010) 'Efisiensi seleksi awal pada kebun benih semai Eucalyptus pellita', Jurnal Penelitian Hutan Tanaman, pp. 1-13. doi: 10.20886/jpht.2010.7.1.1-13.

Mindawati, N. (2011) Analisis Struktur, Perilaku dan Kinerja Industri Pulp dan Kertas di Indonesia Kajian Kualitas Tapak Hutan Tanaman Industri Hibrid Eucalyptus urograndis sebagai Bahan Baku Industri Pulp dalam Pengelolaan Hutan Lestari: Studi Kasus di PT Toba Pulp Lestari, . Institut Pertanian Bogor.

Pasaribu, R. . and Tampubolon, A. P. (2007) 'Status Teknologi Pemanfaatan Serat Kayu Untuk Bahan Baku Pulp', in Workshop Sosialisasi Program dan Kegiatan BPHPS Guna Mendukung Kebutuhan Riset Hutan Tanaman Kayu Pulp dan Jejaring Kerja.

Putra, E. . (2009) Analisis Struktur, Perilaku dan Kinerja Industri Pulp dan Kertas di Indonesia. Institut Pertanian Bogor.

Putra, I., Purnomo, S. and Widiyatno (2014) 'Penerapan Sistem Silvikultur Dengan Prinsip-Prinsip Kelestarian dalam Pengelolaan Hutan Alam di PT Sari Bumi Kusuma, Kalimantan Tengah', in Prosiding Seminar Nasional Silvikultur II, pp. 41-53.

Suhartati, S. et al. (2013) 'Kajian Dampak Penurunan Daur Tanaman Acacia crassicarpa A. Cunn Terhadap Nilai Produksi dan Sosial', Jurnal Penelitian Hutan Tanaman, 10(2), pp. 109-117. doi: 10.20886/jpht.2013.10.2.109-117.

Suprapti, S., Djarwanto, D. and Pasaribu, R. A. (2008) 'Pemanfaatan Kulit Kayu Mangium dari Limbah Industri Pulp untuk Media Produksi Ganoderma lucidum', Jurnal Penelitian Hasil Hutan, 26(3), pp. 263-276. doi: 10.20886/JPHH.2008.26.3.263 - 276.

Tambunan, M. (2005) 'Restrukturisasi Industri Kehutanan Menuju Industri Hutan Berbasis IKM di Indonesia', Jurnal Kebijakan Ekonomi, 1(1), pp. 37-58. 
The International Bank for Reconstruction and Development, - (2006) Sustaining Economic Growth, Rural Livelihoods, and Environmental Benefits: Strategic Options for Forest Assistance in Indonesia. Jakarta: THE WORLD BANK.

Wahyuni, T. and Indriyanti, S. Y. (2015) 'Analisis Finansial Usaha Pengembangan Jenis Dipterokarpa dengan Sistem Tebang Pilih Tanam Indonesia', Jurnal Penelitian Ekosistem Dipterokarpa, 1(1), pp. 41-54. doi: 10.20886/jped.2015.1.1.41-54.
Yuniati, D. (2011) 'Analisis Finansial Dan Ekonomi Pembangunan Hutan Tanaman Dipterokarpa dengan Teknik Silin (Studi Kasus PT. Sari Bumi Kusuma, Kalimantan Barat)', Jurnal Penelitian Hutan Tanaman, 8(4), pp. 239-249. doi: 10.20886/ jpht.2011.8.4.239-249. 